\title{
E-Participation and E-Government Maturity: A Global Perspective
}

\author{
Satish Krishnan ${ }^{1}$, Thompson S.H. Teo ${ }^{1,2}$, and John Lim ${ }^{1}$ \\ ${ }^{1}$ Department of Information Systems, School of Computing \\ ${ }^{2}$ Department of Decision Sciences, School of Business \\ National University of Singapore, Singapore \\ \{satishk, tteo, jlim\}@ comp.nus.edu.sg
}

\begin{abstract}
Utilizing the Technology-Organization-Environment (TOE) theory and the literature on citizen engagement (or participation), we formulated a multiple-mediation model, examining (1) the contextual antecedents of e-participation and e-government maturity; and (2) the mediating role of eparticipation (in form of e-information sharing, e-consultation, and e-decisionmaking) on the relationships between the TOE contextual factors and e-government maturity. Based on archival data from 187 countries, our results showed that ICT infrastructure, human capital and e-participation had a direct relationship with e-government maturity. Of the three dimensions of eparticipation, e-information sharing and e-decision-making were positively associated with e-government maturity, and e-consultation was negatively related. Further, all three dimensions of e-participation partially mediated the influence of ICT infrastructure and human capital on e-government maturity. Results also indicated that governance in a country did not significantly contribute to its e-government maturity, and their relationship was not mediated by e-participation. Our findings contribute to the theoretical discourse on egovernment by identifying the contextual factors affecting e-government maturity, and provide indications to practice on enhancing government's willingness in implementing relevant e-participation initiatives.
\end{abstract}

Keywords: ICT infrastructure, human capital, governance, e-participation, egovernment maturity.

\section{Introduction}

E-government can be defined as the delivery of government information and services using the Internet or other digital means (Krishnan and Teo 2012). Research on egovernment can be classified into three broad streams, namely, evolution and development, adoption and implementation, and impact on stakeholders (Srivastava 2011). While there is a vast amount of research carried out in these three areas, most studies were concerned with specific aspects of e-government in reference to specific region or country (Srivastava and Teo 2008). Although the need for considering a macro-level (i.e., cross-country level) perspective is largely stressed in past literature (Srivastava and Teo 2010), researchers with few exceptions (e.g., Krishnan and Teo 
2012), ignored or overlooked them due to the lack of cumulative theoretical development in e-government research (Heeks and Bailur 2007) to devise an empirical study addressing macro-level issues. Predicated by this concern, the present study addresses the need for conducting cross-country quantitative empirical study.

E-government maturity in a country represents the extent to which a government has established an online presence (West 2007). Implicitly, it constitutes a continuum of developmental stages, from publishing information to supporting transactions, with some countries having progressed further than others (West 2007). Despite numerous motivations and service targets underlying public institutions, furthering egovernment, and reaching the stage of maturity is a challenging task faced by government agencies in most countries. Motivated by this challenge faced by majority of governments, a major purpose of this study is to identify the country-level factors influencing e-government maturity.

It is widely acknowledged that "citizen engagement" is key to growth and maturity of e-government (Chan and Pan 2008; Olphert and Damodaran 2007). The concept of citizen engagement is exercised through e-participation, which involves the extension and transformation of participation in societal democratic and consultative process mediated by ICTs and the Internet (Saebo et al. 2008). Emerging research on eparticipation is limited in two ways. First, most studies remain - except a few recent studies - at best anecdotal, conjectural, and descriptive. While such studies offer benchmarks for practitioners to assess and evaluate their practices pertaining to eparticipation, they provide little value to theory. Second, among few recent studies, most (e.g., Hartwick and Barki 2001) focus on the demand side of e-participation (i.e., citizens' perspective) rather than the supply side (i.e., governments' perspective). Motivated by the fact that there is a dearth of macro-level studies examining eparticipation from supply side, in this study, we focus on the $\mathrm{G} 2 \mathrm{C}$ aspect of participation, and adopt the definition as defined by the UN; e-participation is defined as the willingness of a government (and its agencies) to use online tools (e.g., email and discussion forums) for the specific purpose of empowering people for able participation in consultations and decision-making, both in their capacity as consumers of public services and as citizens (UN-Report 2005).

E-participation consists of three dimensions, namely, e-information sharing, econsultation, and e-decision-making (UN-Report 2005). E-information sharing is concerned with the willingness of governments to offer tools (e.g., web forums, email lists, newsgroups and chat rooms) for dissemination of information (e.g., list of elected officials, policies and programs, and point of contact) on their websites for timely access and use by citizens. E-consultation is concerned with the willingness of governments to encourage their citizens to participate in discussions by offering a choice of public policy topics online with real time and archived access to audios and videos of public meetings. Finally, e-decision-making is related to governments' willingness in indicating that it will take its citizens' e-inputs into account in decisionmaking, and provide actual feedback on the outcome of specific issues. A recent study conducted by the UN highlighted that e-participation is still in a "nascent state" indicating disconnectedness between government and its citizens (UN-Report 2010). Given that e-participation plays a pivotal role in growth and maturity of e-government (Chan and Pan 2008) by serving as a mechanism to manage the development of 
e-government services (Olphert and Damodaran 2007); it is necessary to identify the determinants that facilitate countries to attain varying levels of e-participation.

With these motivations, using the Technology-Organization-Environment (TOE) theory (Tornatzky and Fleischer 1990) as a guiding theoretical lens, we identify the contextual factors facilitating e-participation (in form of e-information sharing, econsultation, and e-decision-making) and e-government maturity in a nation. Further, by drawing from the citizen engagement literature, we investigate the effects of einformation sharing, e-consultation, and e-decision-making on e-government maturity, and the mediating effects of e-information sharing, e-consultation, and edecision-making on the relationships between the TOE factors and e-government maturity. In sum, the research questions are: (1) What TOE contextual factors facilitate e-participation and e-government maturity? (2) What is the relationship between e-participation and e-government maturity? (3) How does e-participation mediate the effects of TOE contextual factors on e-government maturity?

The rest of the paper is organized as follows. In the ensuing section, we present our theoretical background and hypotheses. This is followed by a section on research design. Thereafter, using archival data from 187 countries, we test the hypothesized model. We then discuss the results and the implications for future research. The final section provides concluding remarks with a restatement of the value of the work.

\section{Theory and Hypotheses}

We use the theoretical framework proposed by Tornatzky and Fleischer (1990) as our foundation. According to them, innovation adoption or technology deployment in a firm is influenced by three contexts, namely, technological context, organizational context, and environmental context. Based on our review of academic (e.g., Krishnan and Teo 2012; Siau and Long 2009) and practitioner literature (e.g., UN-Report 2003; 2010) on e-government, we identify three factors that might be influential in facilitating e-participation and e-government maturity in a country (see Fig. 1): (1) ICT infrastructure; (2) human capital; and (3) governance. These three factors correspond to the three contexts defined in the TOE theory. ICT infrastructure is the gradual convergence of broadcasting content, telecommunications, and computing (Tapscott 1996). Human capital, on the other hand, refers to the knowledge, skills, and abilities embodied in people (here, citizens) (Coff 2002). Governance is defined as the traditions and institutions by which authority in a country is exercised (Kaufmann et al. 1999). We next derive and explain each hypothesis.

\subsection{ICT Infrastructure, E-Government Maturity, and E-Participation}

According to neoclassical and new growth theories, technological progress and creativity is a critical determinant of growth and development (Lucas 1988; Romer 1990). Extending this argument in the context of e-government, we argue that ICT infrastructure can contribute towards the growth and maturity of e-government systems as e-government needs to utilize the information infrastructure to deliver online public services (Siau and Long 2009). In a similar vein, Srivastava and Teo 
(2010) stressed that government and its agencies can fulfill their duties related to the daily activities of citizens and businesses only when they are connected with the citizens and businesses, which indeed is possible only with a sound ICT infrastructure. Warkentin et al. (2002) emphasized that e-government is characterized by extensive use of ICTs that stimulates the growth and maturity of e-government. Koh et al. (2005) and Singh et al. (2007) highlighted that reaching the stage of egovernment maturity will remain an "unrealized dream" in the absence of sound and reliable ICT infrastructure. Hence, we posit: 'H1: ICT infrastructure in a country is positively associated with its e-government maturity.'

For governments to be more willing to implement e-participation initiatives, robust ICT infrastructure that allows citizens access to decision makers is required (UNReport 2005). Meso et al. (2009) indicated that the availability of ICTs (1) allows greater access by the population to government services; (2) facilitates public participation in policy-making process by rapidly disseminating news and information to the citizens; and (3) eliminates or minimizes barriers to participation in the country's economic markets. Further, information infrastructure (e.g., Web 2.0) plays a critical role in empowering citizens to become more active in expressing their views on issues concerning environment, health, education and other areas of government policy (UN-Report 2010). In sum, a government's willingness to (1) request, receive and incorporate feedback from its constituents; and (2) tailor the policy measures to meet the needs and priorities of citizens can be enhanced only when a sound, robust and reliable ICT infrastructure is in place. Therefore, we propose: ' $H 2$ : ICT infrastructure in a country is positively associated with its (H2a) e-information sharing; (H2b) e-consultation; and (H2c) e-decision-making.'

\subsection{Human Capital, E-Government Maturity, and E-Participation}

Human capital indicates how well educated are the citizens in a nation. Schultz (1961) and Lewis (1955) in their human capital theory have stressed the critical role of "human capital" in growth and development of individuals and nations. Specifically, Schultz argued that human capital is one of the critical reasons that explain the differences in growth (e.g., income and productivity) between human beings as well as nations. Like human capital theory, the new growth theory also supported knowledge-based economy by recognizing the importance of human capital and indicates that the investment in human capital generates returns in the future (Lucas 1988; Romer 1986). Flak and Rose (2005) indicated that citizens is one of the important stakeholder groups for successfully implementing e-government initiatives, and their knowledge is a valuable resource for e-governments to attain the stage of maturity. Further, Singh et al. (2007) found that human capital is a significant determinant of e-government maturity, and Srivastava and Teo (2010) established that human capital (in terms of education and training) in a country is positively associated with the level of its e-government. Therefore, we propose: 'H3: Human capital in a country is positively associated with its e-government maturity.'

UN established the expectations of citizens to be directly involved in designing government programs and services (UN-Report 2005). That is, at various stages of policy process, from elections to policy planning and implementation, citizens are 
becoming increasingly involved (Phang and Kankanhalli 2008). Such participation is possible only when the citizens have sufficient learning skills and knowledge capabilities embodied within them. This will indeed facilitate governments' willingness to (1) increase e-information sharing; (2) enhance e-consultation; and (3) support e-decision-making. Hence, when citizens are empowered, they are not only able to participate, but also create a different relationship with their respective governments, characterized by enhanced effectiveness (UN-Report 2010). Hence, we posit: 'H4: Human capital in a country is positively associated with its $(\mathrm{H} 4 \mathrm{a}) \mathrm{e}$ information sharing; (H4b) e-consultation; and (H4c) e-decision-making.'

\subsection{Governance, E-Government Maturity, and E-Participation}

Governance refers to the collection of processes and institutions that creates the conditions for ordered rule and collective action (Kazancigil 1998). Madon et al. (2007) established that effective implementation of government-based information systems (IS) for the provision of services is impacted by the macro-level policymaking organs; thereby shaping the type of system that eventually gets implemented. Moon (2002) found that institutional factors significantly contributed to the adoption of e-government among municipalities. Norris and Moon (2005) showed that the level of adoption and sophistication of e-government systems are correlated with the presence of well-developed institutional factors. A study conducted by West (2004) and Srivastava and Teo (2010) highlighted the importance of governance mechanisms in ensuring e-government growth and maturity. As effective governance assures an environment conducive to investment (Meso et al. 2006), we posit: 'H5: Governance in a country is positively associated with its e-government maturity.'

Governance entails public debate and open, participatory decision-making. According to the participatory model of governance in e-government implementation (Chadwick and May 2003), governance is seen as open communications, where the opinions are not directed only to government but to all players within the governance communications space. Hence, governance fosters the collaboration and information sharing among disparate stakeholders. In addition, effective governance ensures an enhanced supply of the desired services, eliminates or minimizes the barriers to participation, and promotes rule of law (Meso et al. 2006). Also, governance provides direction to creation of environment in which citizens can be more active and supportive of their governments, and increase the willingness of governments to use ICTs to provide high quality information and effective communication tools for able participation in consultations and decision-making. Therefore, we propose: ' $H 6$. Governance in a country is positively associated with its (H6a) e-information sharing; (H6b) e-consultation; and (H6c) e-decision-making.'

\subsection{Relating E-Participation to E-Government Maturity}

According to e-government stage models, e-government maturity cannot be thought as a one-step project or implemented as a single project (Siau and Long 2006). The implication from the stage models is that the growth and maturity of e-government is evolutionary in nature and the stages (of growth) are theoretically ascending in the 
level of maturity or sophistication of e-government (UN-Report 2003). Given that citizen engagement via e-participation is pivotal in the evolutionary process of egovernment maturity (Chan and Pan 2008; Olphert and Damodaran 2007), it is logical to presume that as government's willingness to engage its citizens in e-government processes increases, so does the level of e-government maturity in a country. That is, when the government is willing to implement e-participation initiatives, citizens become "active creators" or "feedback providers," thereby contributing information to the success of e-government (Ekelin 2003). This fact is also emphasized in a study by Tan and Pan (2003). According to them, a bureaucratic government organization can move towards anticipative and responsive practices only when it treats its citizens as "strategic value networks" in the process of e-transformation. Further, they stress that such a relationship will not only lead to "total customer satisfaction" but also create "multi-directional strategic value." Consequently, we posit: 'H7. E-participation (H7a. e-information sharing; H7b. e-consultation; and H7c. e-decision-making) in a country is positively associated with its e-government maturity.'

\subsection{Mediated Effects of E-Participation}

Having assembled each of the piecewise elements and relations in our research model (see Fig. 1), we logically deduce one more set of hypotheses. We posit that e-participation (in form of e-information sharing, e-consultation, and e-decisionmaking) serves as an intervening mechanism or, at the least, partial conveyors of the effects of TOE contexts onto e-government maturity. That is, TOE contexts indirectly influence e-government maturity by raising the levels of e-information sharing, econsultation, and e-decision-making. More formally, we therefore offer the following: 'H8: TOE contexts' (H8a. ICT infrastructure; H8b. human capital; and H8c. governance) effects on e-government maturity are mediated by e-information sharing, e-consultation and e-decision-making.'

\section{$3 \quad$ Research Design}

To test the formulated hypotheses, we gathered archival data (for each of the main constructs) as it offers several advantages such as easy reproducibility, ability to generalize the results arising from larger datasets, and robust to the threat of common method bias (Jarvenpaa 1991). Hypotheses were tested via a cross-sectional analysis of 187 countries (after omitting the missing values).

The dependent construct, e-government maturity, reflecting the demonstrated behavior of e-government in a country, is measured as the extent to which a government has established an online presence (West 2007). The scores for this construct were obtained from the Global E-Government Report 2007 (West 2007), and has been used in past academic studies such as Singh et al. (2007). The mediating construct, e-participation was measured on three dimensions: (1) e-information sharing; (1) e-consultation; and (3) e-decision-making. The UN assessed eparticipation (qualitatively with values running between 0 and 1 , with the higher values corresponding to the better results) by measuring the willingness of 
governments to engage citizens in public policy-making through the use of relevant programs (UN-Report 2005). The scores for these three dimensions were obtained from the UN Global E-Government Survey Report 2005 (UN-Report 2005).

The technology construct, ICT infrastructure is indicated by the Telecommunication Infrastructure Index, the values for which were taken from the UN global e-government survey report 2003 (UN-Report 2003). This index is a composite weighted average of six primary indices (PCs/1000 persons, Internet users/1000 persons, telephone lines/1000 persons, online population, mobile phones/1000 persons, and TVs/1000 persons), which define a country's ICT infrastructure capacity. This index has been used in past academic studies like Krishnan and Teo (2012), and Srivastava and Teo (2010). The organizational construct, human capital is indicated by the Education Index, the values (running between 0 and 1, with the higher values corresponding to the higher levels of human capital) for which were obtained from the UN global e-government survey report 2003 (UN-Report 2003). This index is a composite of the adult literacy rate and the combined primary, secondary and tertiary gross enrolment ratio, with two-thirds of the weight given to adult literacy and one-third to the gross enrolment ratio. This index has been used in past academic studies like Srivastava and Teo (2008). The environmental construct, governance was operationalized using six aggregated measures of governance (with values running between -2.5 and 2.5, with the higher values corresponding to the better governance) originally presented in Kaufmann et al. (1999). The measures are: (1) voice and accountability; (2) political stability and absence of violence; (3) government effectiveness; (4) regulatory quality; (5) rule of law; and (6) control of corruption. Data for these measures were taken from the Worldwide Governance Indicators Database, and is for year 2003 (Kaufmann et al. 2010). These measures have been used in past academic studies like Krishnan and Teo (2012), and Meso et al. (2006).

Additional control variables consisted of economic conditions (measured in terms of GDP per capita, adjusted for purchasing power parity) and regional difference, operationalized as the country-level difference across various regions of the world.

\section{$4 \quad$ Analysis and Results}

\subsection{Descriptive Statistics and Correlations}

Table 1 present the descriptive statistics and correlations for all variables. As shown, most correlations were significant at $\mathrm{p}<0.001$. In addition, as correlations were below the threshold value of 0.8 , the concern for multicollinearity would be minimal (Gujarati and Porter 2009). Nevertheless, we followed up with the collinearity tests that measure variance inflation factor (VIF). The results revealed that our VIFs ranged from 1.31 to 3.43 (all tolerance levels above 0.29). As per Fox (1991), a VIF > 4.0, or a tolerance level $<0.25$, may indicate the potential for multicollinearity; thus, the concern in our model appeared to be minimal. 
Table 1. Descriptive statistics and correlations

\begin{tabular}{lcccccccccc}
\hline Variable & Mean & SD & 1 & 2 & 3 & 4 & 5 & 6 & 7 & 8 \\
\hline 1. EC & 7.75 & 1.63 & - & & & & & & \\
2. RD & 2.72 & 1.16 & -29 & - & & & & & \\
3. ICT & 0.18 & 0.21 & 72 & $\frac{-20}{25}$ & - & & & & \\
4. HC & 0.72 & 0.25 & 54 & $\frac{-25}{27}$ & 50 & - & & & \\
5. GOV & -0.08 & 0.91 & 71 & -27 & 73 & 45 & - & & \\
6. EIS & 0.22 & 0.23 & 56 & $\underline{-25}$ & 69 & 45 & 60 & - & \\
7. ECN & 0.13 & 0.22 & 46 & $\underline{-20}$ & 61 & 39 & 49 & 71 & - \\
8. EDM & 0.13 & 0.19 & 50 & $\underline{-21}$ & 65 & 38 & 54 & 69 & 70 & - \\
9. EGM & 28.01 & 4.61 & 66 & $\underline{-22}$ & 68 & 57 & 53 & 70 & 71 & 68 \\
Note: & aLog transformed variable; N $=187$; EC: Economic Condition; RD: Regional \\
Difference; ICT: ICT Infrastructure; HC: Human Capital; GOV: Governance; EIS: E- \\
Information Sharing; ECN: E-Consultation; EDM: E-Decision-Making; EGM: E- \\
Government Maturity; Decimal points are omitted for correlations; All correlations \\
(except underlined) are significant at p < 0.001 and underlined correlations are \\
significant at p < 0.01.
\end{tabular}

\subsection{Hypotheses Testing}

Given the importance of the mediating effects in our research model, it is necessary to conduct a systematic analysis exploring these effects. Since the research model has more than one mediator, this study refers to the method that Preacher and Hayes (2008) recommended for testing multiple-mediator models. A Preacher and Hayes analysis includes an examination of the total and direct effects of the independent variable on the dependent variable, the difference between which is the indirect effect of the independent variable on the dependent variable through mediators. The analysis also yields an estimation of the indirect effect of each mediator. In addition, the biascorrected (BC) bootstrap will generate a 95\% confidence interval (CI) for each mediator. If the interval for a mediator does not contain zero, it means the indirect effect of this mediator is significantly different from zero. In addition, a contrast between two mediators shows how their indirect effects can be distinguished in terms of magnitude. Fig. 1 shows the regression results.

As shown in Fig. 1, the results revealed that the paths from ICT infrastructure to egovernment maturity $(\beta=0.78, \mathrm{p}<0.001)$ and from human capital to e-government maturity $(\beta=0.23, \mathrm{p}<0.001)$ were significant. Hence, $\mathrm{H} 1$ and $\mathrm{H} 3$ were supported. As the path from governance to e-government maturity $(\beta=0.03$, n.s. $)$ was not significant, H5 was not supported. Results also revealed that the paths from ICT infrastructure to e-information sharing $(\beta=0.81, \mathrm{p}<0.001)$, e-consulting $(\beta=0.76, \mathrm{p}$ $<0.001)$ and e-decision-making $(\beta=0.65, \mathrm{p}<0.001)$ were all significant. This confirmed H2a, H2b, and H2c. Similarly, while the paths from human capital to einformation sharing $(\beta=0.15, \mathrm{p}<0.01)$ and e-consulting $(\beta=0.12, \mathrm{p}<0.05)$ were significant, the path concerning e-decision-making was not significant $(\beta=0.08$, n.s.). Hence, $\mathrm{H} 4 \mathrm{a}$ and $\mathrm{H} 4 \mathrm{~b}$ were supported and $\mathrm{H} 4 \mathrm{c}$ was not supported. Further, the paths from governance to e-information sharing $(\beta=0.03$, n.s. $)$, e-consulting $(\beta=0.01$, n.s. $)$ and e-decision-making ( $\beta=0.02$, n.s.) were not significant. Hence, H6a, H6b, and H6c were not supported. Lastly, the paths from e-information sharing $(\beta=0.60$, 
$\mathrm{p}<0.001)$, e-consultation $(\beta=-0.23, \mathrm{p}<0.05)$, and e-decision-making $(\beta=0.27, \mathrm{p}<$ $0.01)$ to e-government maturity were all significant. However, while the direction of the relationships of e-information sharing and e-decision-making with e-government maturity was consistent with our initial prediction, the direction of the relationship between e-consultation and e-government maturity was contrary to our initial prediction. Hence, $\mathrm{H} 7 \mathrm{a}$ and $\mathrm{H} 7 \mathrm{c}$ were supported, and $\mathrm{H} 7 \mathrm{~b}$ was not supported. While unexpected, this finding is interesting and will be discussed in greater detail in the next section. Finally, the control variables, economic conditions $(\beta=-0.004$, n.s.) and regional differences $(\beta=0.003$, n.s.) were not significantly associated with egovernment maturity.

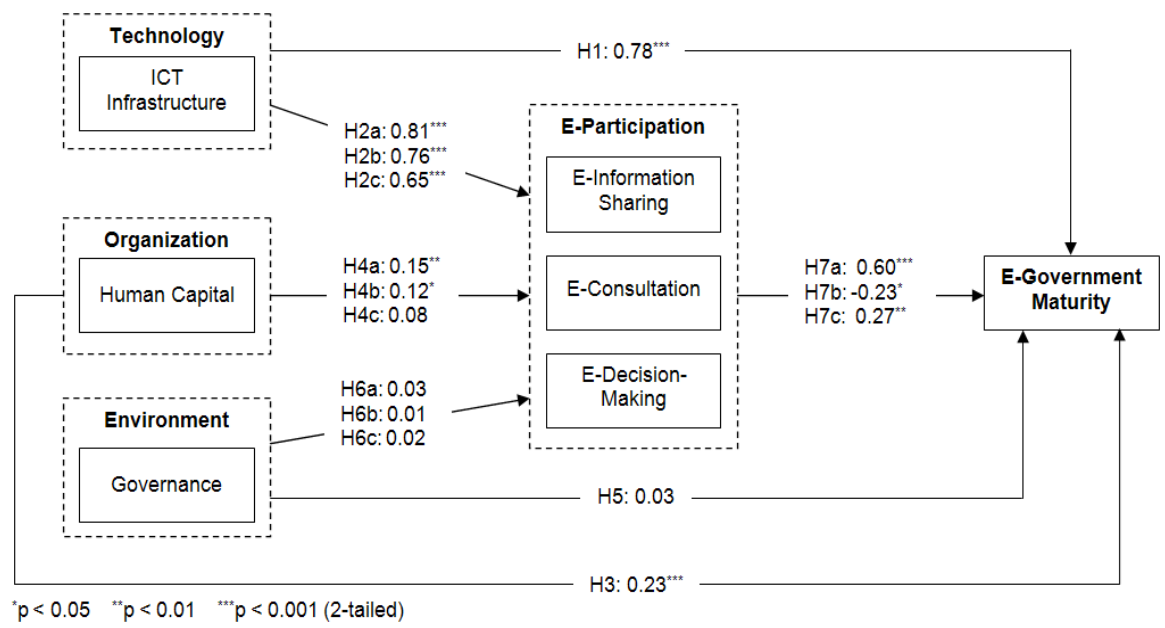

Fig. 1. Regression results

Table 2 presents the mediation results. First, model 1 was examined, in which ICT infrastructure was the independent variable with human capital and governance treated as covariates. Next, model 2 was examined, in which human capital was the independent variable with ICT infrastructure and governance treated as covariates. As shown in Table 2, ICT infrastructure [human capital] had a significant total effect on e-government maturity. When the mediators were introduced, the direct effect of ICT infrastructure [human capital] on e-government maturity remained significant. This meant that e-information sharing, e-consultation, and e-decision-making partially mediated the impact of ICT infrastructure [human capital] on e-government maturity. Furthermore, the difference between the total and direct effects was the total indirect effect as mediated through e-information sharing, e-consultation, and e-decisionmaking, with a point estimate of 0.4974 [0.0861] and a 95\% BC bootstrap CI of 0.3435 to 0.6783 [0.0287 to 0.1543 ]. Since the CI did not contained zero, the total indirect effect was different from zero. An examination of the specific indirect effects indicated that e-information sharing, e-consultation, and e-decision-making were mediators as their $95 \%$ CIs did not contain zero. The point estimate of the indirect impact through e-information sharing and e-consultation were 0.4965 [0.0932] and 0.1800 [-0.0298] respectively, and of that through e-decision-making was 0.1809 
[0.0226]. Examination of the pairwise contrasts of the indirect effects (i.e., C1, C2, and C3 in model 1 [2] of Table 2) showed that (1) the specific indirect effect through e-information sharing was larger than the specific indirect effect through econsultation, with a BC $95 \%$ CI of 0.3281 to 1.1492 [0.0477 to 0.2437 ]; (2) the specific indirect effect through e-information sharing was larger than the specific indirect effect through e-decision-making, with a BC $95 \%$ CI of 0.0220 to 0.6512 [0.0130 to 0.1513]; and (3) the specific indirect effect through e-consultation was larger than the specific indirect effect through e-decision-making, with a BC $95 \% \mathrm{CI}$ of -0.7436 to -0.0348 [-0.1325 to -0.0048$]$. In sum, H8a [H8b] was supported.

Table 2. Mediation results

\begin{tabular}{|c|c|c|c|c|c|c|c|c|}
\hline \multicolumn{2}{|c|}{$\begin{array}{l}\text { Total Effect of IV } \\
\text { on DV }\end{array}$} & \multicolumn{2}{|c|}{$\begin{array}{l}\text { Direct Effect of IV } \\
\text { on DV }\end{array}$} & \multicolumn{5}{|c|}{ Indirect Effects } \\
\hline \multirow{2}{*}{$\mathrm{COEF}$} & \multirow{2}{*}{$\mathrm{TV}$} & \multirow{2}{*}{$\mathrm{COEF}$} & \multirow{2}{*}{ TV } & & & \multirow{2}{*}{$\mathrm{PE}$} & \multicolumn{2}{|c|}{ BC 95\% CI } \\
\hline & & & & & & & Lower & Upper \\
\hline \multicolumn{9}{|c|}{ Model 1: ICT Infrastructure as IV } \\
\hline \multirow[t]{7}{*}{$0.7801^{* * * *}$} & \multirow[t]{7}{*}{6.9609} & \multirow[t]{7}{*}{$0.2912^{* *}$} & \multirow[t]{7}{*}{2.8892} & \multicolumn{2}{|l|}{ Total } & 0.4974 & 0.3435 & 0.6783 \\
\hline & & & & \multirow{3}{*}{ MED } & EIS & 0.4965 & 0.2705 & 0.7601 \\
\hline & & & & & ECN & -0.1800 & -0.4219 & -0.0066 \\
\hline & & & & & EDM & 0.1809 & 0.0096 & 0.3756 \\
\hline & & & & \multirow{3}{*}{$\mathrm{CON}$} & $\mathrm{C} 1$ & 0.6765 & 0.3281 & 1.1492 \\
\hline & & & & & $\mathrm{C} 2$ & 0.3156 & 0.0220 & 0.6512 \\
\hline & & & & & C3 & -0.3609 & -0.7436 & -0.0348 \\
\hline \multicolumn{9}{|c|}{ Model 2: Human Capital as IV } \\
\hline \multirow[t]{7}{*}{$0.2374^{* * * *}$} & \multirow[t]{7}{*}{4.2752} & \multirow[t]{7}{*}{$0.1513^{* * *}$} & \multirow[t]{7}{*}{3.4035} & \multicolumn{2}{|l|}{ Total } & 0.0861 & 0.0287 & 0.1543 \\
\hline & & & & \multirow{3}{*}{ MED } & EIS & 0.0932 & 0.0351 & 0.1769 \\
\hline & & & & & ECN & -0.0298 & -0.0774 & -0.0008 \\
\hline & & & & & EDM & 0.0226 & 0.0005 & 0.0664 \\
\hline & & & & \multirow{3}{*}{$\mathrm{CON}$} & $\mathrm{C} 1$ & 0.1230 & 0.0477 & 0.2437 \\
\hline & & & & & $\mathrm{C} 2$ & 0.0706 & 0.0130 & 0.1513 \\
\hline & & & & & C3 & -0.0524 & -0.1325 & -0.0048 \\
\hline \multicolumn{9}{|c|}{ Model 3: Governance as IV } \\
\hline \multirow[t]{7}{*}{0.0318} & \multirow[t]{7}{*}{1.2747} & \multirow[t]{7}{*}{0.0068} & \multirow[t]{7}{*}{0.3436} & \multicolumn{2}{|l|}{ Total } & 0.0251 & -0.0017 & 0.0562 \\
\hline & & & & & EIS & 0.0230 & -0.0009 & 0.0538 \\
\hline & & & & MED & ECN & -0.0031 & -0.0213 & 0.0060 \\
\hline & & & & & EDM & 0.0051 & -0.0042 & 0.0295 \\
\hline & & & & & $\mathrm{C} 1$ & 0.0260 & -0.0044 & 0.0711 \\
\hline & & & & $\mathrm{CON}$ & $\mathrm{C} 2$ & 0.0178 & -0.0003 & 0.0454 \\
\hline & & & & & C3 & -0.0082 & -0.0459 & 0.0102 \\
\hline $\begin{array}{l}\text { Note: } \mathrm{N}= \\
\text { Variable; } \\
\text { Point Estir } \\
\text { relation be } \\
\text { other varia } \\
\text { terms of } \mathrm{m} \\
\text { Making; } \\
\text { Decision-I }\end{array}$ & $\begin{array}{l}87 ; 5000 \\
\text { V: Depe } \\
\text { ate; BC: } \\
\text { ween ind } \\
\text { les; 'CO } \\
\text { gnitude; } \\
\text { : E-Info } \\
\text { laking; C }\end{array}$ & $\begin{array}{l}\text { dent } V \text { aria } \\
\text { Bias-Corre } \\
\text { pendent v } \\
\text { J (Contras } \\
\text { EIS: E-Info } \\
\text { nation Sha } \\
\text { : E-Consu }\end{array}$ & $\begin{array}{l}\text { mples; R } \\
\text { e; MED: } \\
\text { ed Boots } \\
\text { able and } \\
\text { indicate } \\
\text { nation S } \\
\text { ng vs. E- } \\
\text { tion vs. }\end{array}$ & $\begin{array}{l}=78 \% \\
\text { Mediato } \\
\text { ap; CI: } \\
\text { epende } \\
\text { if the in } \\
\text { aring; E } \\
\text { onsulta } \\
\text {-Decisi }\end{array}$ & $\begin{array}{l}\text { djustec } \\
\text {; COE } \\
\text { onfider } \\
\text { variab } \\
\text { irect ef } \\
\mathrm{N} \text { : E-C } \\
\text { on; C2: } \\
\text { 1-Makil }\end{array}$ & $\begin{array}{l}\mathrm{R}^{2}=77 \% \\
\text { Coefficie } \\
\text { e Interval } \\
\text { without } \\
\text { cts could } \\
\text { nsultation } \\
\text {-Informa } \\
{ }^{* *} \mathrm{p}<0 .\end{array}$ & $\begin{array}{l}\text { IV: Indep } \\
\text { t; TV: T- } \\
\text { 'Total' is } \\
\text { e conside } \\
\text { e distingu } \\
\text { EDM: E- } \\
\text { on Sharin } \\
{ }^{* * *} \mathrm{p}<0 .\end{array}$ & $\begin{array}{l}\text { ndent } \\
\text { alue; PE: } \\
\text { te total } \\
\text { tion of } \\
\text { hed in } \\
\text { ecision- } \\
\text { vs. E- }\end{array}$ \\
\hline
\end{tabular}


Next, model 3 was examined, in which governance was the independent variable with ICT infrastructure and human capital treated as covariates. As shown in Table 2, governance did not have a significant total effect on e-government maturity. While some researchers (e.g., Baron and Kenny 1986) suggested that a significant total effect of the independent variable on the dependent variable is a prerequisite for testing the mediating effects, others (e.g., Shrout and Bolger 2002) argued that this is not necessary. Thus, we continued to examine the mediating effects. However, as shown in Table 2 (model 3), the total indirect effects were not significant, with a point estimate of 0.0251 and a $95 \%$ BC CI of -0.0017 to 0.0562 . Examination of the specific indirect effects showed that neither of the e-participation variables were mediators, since their $95 \%$ CIs contained zero. Hence, H8c was not supported.

\section{Discussion}

Our findings raise several issues that deserve mention. First, the level of ICT infrastructure in a country significantly contributed to its e-participation and egovernment maturity. Within e-participation, the effect of ICT infrastructure was positively associated with all the three dimensions of e-participation. Further, the relationship between the levels of ICT infrastructure and e-government maturity was partially mediated by all the three dimensions of e-participation. Thus, the availability of robust, reliable and sound ICT infrastructure will not only facilitate the growth and maturity of online public services (Siau and Long 2009; Srivastava and Teo 2010) but also enhance the willingness of governments to engage its citizenry in e-government process. Hence, this result suggests that when a country's investment in ICT infrastructure increases (1) its e-government should be able to attain maturity; and (2) it should be more willing to encourage the public to be active in promoting participatory decision-making in public policy matters.

Second, human capital in a country was positively associated with its eparticipation and e-government maturity. Within e-participation, while the effect of human capital facilitated e-information sharing and e-consultation, there was no relationship between human capital and e-decision-making. Further, the effect of human capital was stronger in e-information sharing than in e-consultation. While our study did not come to the expected conclusions with respect to the influence of human capital in a country on the dimensions of e-participation, given its positive associations, we suggest that stimulating the evolution of human consciousness and emergence of mentally self-conscious individuals in a country via education and training will facilitate the maturity of e-government systems and enhancement of eparticipation for promoting citizen engagement. Mediation results also indicated that the relationship between the levels of human capital and e-government maturity was partially mediated by all the three dimensions of e-participation.

Third, our results indicated that governance in a country had little impact on egovernment maturity and on all the dimensions of e-participation. While strong positive correlations (see Table 1) of governance with e-government maturity and eparticipation variables suggested strong positive relationships between them, the 
results indicated that the technological and organizational contexts in the form of ICT infrastructure and human capital respectively were pivotal for e-government maturity and e-participation, compared to the environmental context, governance. Further, mediation results indicated that the relationship between the levels of governance and e-government maturity was not mediated by e-participation. Though several past studies (e.g., Moon 2002; Norris and Moon 2005; Srivastava and Teo 2010) had suggested governance as a significant determinant and contributor to e-government, our study did not elicit a similar result. However, it is gratifying that our findings (though not statistically significant) are in the same direction as past studies.

Finally, turning to the relationship between e-participation and e-government maturity, our results indicated that of the three e-participation dimensions, e-information sharing and e-decision-making were positively associated with egovernment maturity, and e-consultation was negatively associated. Further, between e-information-sharing and e-decision-making, the former had a stronger positive association with e-government maturity than the latter. One possible reason for variations in results may be due to the relative differences in perceived threats (e.g., implementation delays) associated with deployment of various e-participation initiatives. In sum, our results suggest that not all dimensions of e-participation will positively contribute to the growth and maturity of e-government in a country.

Our study makes several key contributions. To theory, we extend and enrich the TOE theory in three ways. First, via theoretical synthesis, we combine the attributes of the TOE theory with the citizen engagement perspective to study the phenomenon of e-government maturity. Second, while the TOE theory has served as a useful theoretical lens for understanding innovation adoption in firms, our study is one among the few studies to extend its theoretical arguments in the global context and to explore its usefulness at the macro-level. Third, while most studies applying the TOE theory have used primary survey data for analyses, our study is among the few studies to demonstrate its applicability by making an innovative use of publicly available archival data. In sum, this study heeds the call of researchers (e.g., Baker 2011) to extend and enrich TOE theory via approaches such as theoretical synthesis.

Our study also contributes to research on e-government and e-participation in three ways. First, while much research has been carried out in all three streams of egovernment research (i.e., evolution and development, adoption and implementation, and impact on stakeholders), most of them addressed research questions that are "micro" in orientation. That is, there is a paucity of research investigating the determinants of e-government maturity from a global perspective (Siau and Long 2009). Realizing the need for conducting cross-country quantitative empirical research, our study identified the contextual factors facilitating the maturity of egovernment in a country. Second, while most extant studies on e-participation looked into the demand side of participation, our study offered a supply side view of participation. Specifically, by drawing from citizen engagement perspective, our study (1) has strived to further our understanding as to why differing levels of egovernment maturity among countries continues to prevail; and (2) emphasize that the willingness of government (and its agencies) in a country to deploy e-participation initiatives will serve as a "mechanism" through which the growth and maturity of 
e-government projects could be managed. Third, by a deeper analysis of the mechanism of e-participation based on its dimensions (i.e., e-information sharing, econsultation, and e-decision-making), our study indicate that the willingness of a government to deploy e-participation initiatives varies based on the nature and purpose of the e-participation activity, which in turn affects the maturity of egovernment.

From a practical standpoint, our study offers several important insights. First, by identifying the determinants of e-government maturity in a country, our study not only facilitates to understanding of why differing levels of growth and maturity of egovernment continues to prevail but also shows directions for attaining the stage of maturity. Specifically, our findings suggest that through investments in technological and human capabilities, it might be possible for a country to move up the ladder of egovernment maturity. Second, by identifying the facilitators of e-participation in a country, our study helps practitioners showing directions to increase governments' willingness towards deployment of e-participation initiatives. Specifically, ICT infrastructure and human capital in a country over its governance are critical determinants of e-participation. Third, our findings indicate that all dimensions of eparticipation play significant roles in affecting e-government maturity. Specifically, while e-information sharing and e-decision making contributes positively to e-government maturity, e-consultation negatively affects the growth and maturity of e-government in a country. These findings suggest to practitioners that while econsultation might provide feedback on e-government process, it is vital for practitioners to realize that it might delay e-government from reaching the stage of maturity. Thus, our findings suggest that e-consultation is a double-edged mechanism.

This study has three major limitations. First, we used archival data obtained from different sources. While primary data might have given us a better control over the definition of variables, it is less feasible for a small group of researchers to undertake a large scale cross-country data collection given the limited amount of resources and time. However, considering the fact that the data have been collected by reputable and authorized organizations, and the indices have been formulated using suitable statistical procedures to ensure the reliability and validity; relying on these secondary sources provides a cost-effective way for conducting our study. Second, we analyzed data only from the countries commonly available in all the primary sources. For instance, we could not include countries like Hong Kong and Taiwan as these countries were not commonly available in all the data sources. However, given that we have only seven main variables and sample size as 187 , discarding few countries may not make a significant difference in the results. Further, bootstrapping approach to mediation with a sample size of 100 and above will detect fairly small R-square values $(10 \%-15 \%)$ with up to 10 independent variables and a significance level of 0.05 (Hair et al. 2006). Third, while e-participation scores for later years (e.g., 2010) are available, we used the scores from the UN Global E-Government Survey Report published in 2005 as the reports published in later years offered only an aggregate score for e-participation rather than scores for individual dimension within eparticipation. However, considering the fact that e-participation is still in a "nascent state" (UN-Report 2010), we believe that the concern for direction and strength of the relationship among variables (due to the usage of e-participation data from earlier 
report) would be minimal. Despite these potential limitations, our study is one among the few studies with macro-level orientation striving to address the knowledge gaps described in the earlier sections of this paper.

Future research may focus on several directions. First, while our study has mainly focused on the antecedents of e-government maturity, future studies may consider examining its consequences (i.e., payoffs). Further, researchers may also consider studying both antecedents and consequences jointly by integrating them cohesively in a unified theoretical framework (e.g., Srivatsava and Teo 2010). Second, given the differences in relationships between the dimensions of e-participation and egovernment maturity, future researchers may also test how the relationships are affected by introducing several contingency variables such as public institutions and macro-economy (e.g., Krishnan and Teo 2012; Srivatsava and Teo 2008).

\section{Concluding Remarks}

In conclusion, despite an extensive recognition on the importance of e-participation and e-government maturity in a nation as a predictor of its growth and performance, both research and practitioner communities knows relatively little with regards to managing e-government maturity. As an initial step to be taken towards raising awareness for the pivotal role of e-participation in managing e-government maturity, we have constructed and validated a theoretical model (specifically, a multiple mediation model) that examined the effects of the TOE contextual factors on eparticipation and e-government maturity. In addition, we reasoned and demonstrated empirically the relationships of different dimensions of e-participation on egovernment maturity, and the mediating role of e-participation variables on the relationships between TOE contextual factors and e-government maturity.

\section{References}

Barker, J.: The Technology-Organization-Environment Framework. In: Dwivedi, Y., Wade, M., Schneberger, S. (eds.) Information Systems Theory: Explaining and Predicting our Digital Society, vol. 1, pp. 231-246. Springer, New York (2011)

Baron, R.M., Kenny, D.A.: The Moderator-Mediator Variable Distinction in Social Psychological Research: Conceptual, Strategic, and Statistical Considerations. Journal of Personality and Social Psychology 51, 1173-1182 (1986)

Chadwick, A., May, C.: Interactions between States and Citizens in the Age of the Internet: 'Egovernment' in the United States, Britain and the European Union. Governance 16, 271-300 (2003)

Chan, M.L., Pan, S.L.: User Engagement in E-Government Systems Implementation: A Comparative Case Study of Two Singaporean E-Government Initiatives. Journal of Strategic Information Systems 17, 124-139 (2008)

Coff, R.W.: Human Capital, Shared Expertise, and the Likelihood of Impasse in Corporate Acquisitions. Journal of Management 28, 107-128 (2002)

Ekelin, A.: Working with the Fogbow: Design and Reconfiguration of Services and Participation in E-government. Licentiate Dissertation. Blekinge Institute of Technology, Sweden (2003) 
Flak, L.S., Rose, J.: Stakeholder Governance: Adapting Stakeholder Theory to E-Governance. Communications of the Association for Information Systems 16, 662-664 (2005)

Fox, J.: Regression Diagnostics, Newbury Park. Sage, CA (1991)

Gujarati, D.N., Porter, D.C.: Basic Econometrics. McGraw-Hill, New York (2009)

Hair, J.F., Anderson Jr., R.E., Tatham, R.L., Black, W.C.: Multivariate Data Analysis with Readings. Prentice Hall, Englewood Cliffs (2006)

Hartwick, J., Barki, H.: Communication as a Dimension of User Participation. IEEE Transactions on Professional Communication 44, 21-36 (2001)

Heeks, R., Bailur, S.: Analyzing E-government Research: Perspectives, Philosophies, Theories, Methods, and Practice. Government Information Quarterly 24, 243-265 (2007)

Jarvenpaa, S.: Panning for Gold in Information Systems Research: 'Second-Hand' Data. In: Nissen, H.E., Klein, H., Hirschheim, R. (eds.) Information Systems Research: Contemporary Approaches and Emergent Traditions, IFIP TC/WG 8.2, pp. 63-80. Alfred Waller Ltd., North Holland (1991)

Kaufmann, D., Kraay, A., Mastruzz, M.: The Worldwide Governance Indicators: Methodology and Analytical Issues. Draft Policy Research Working Paper, The World Bank Development Research Group, Washington, DC (2010)

Kaufmann, D., Kraay, A., Zoido-Lobotan, P.: Governance Matters. Policy Research Working Paper 2196, The World Bank Development Research Group, Washington, DC (1999)

Kazancigil, A.: Governance and Science: Market-like Modes of Managing Society and Producing Knowledge. International Social Science Journal 50, 69-79 (1998)

Koh, C.E., Ryan, S., Prybutok, V.R.: Creating Value through Managing Knowledge in an EGovernment to Constituency (G2C) Environment. Journal of Computer Information Systems 45, 32-41 (2005)

Krishnan, S., Teo, T.S.H.: Moderating Effects of Governance on Information Infrastructure and E-government Development. Journal of the American Society for Information Science and Technology 63, 1929-1946 (2012)

Lewis, W.A.: The Theory of Economic Growth, Irwin, Homewood, Ill (1995)

Lucas, R.E.: On the Mechanics of Economic Development. Journal of Monetary Economics 22, 3-42 (1988)

Madon, S., Sahay, S., Sudan, R.: E-Government Policy and Health Information Systems Implementation in Andhra Pradesh, India: Need for Articulation of Linkages between the Macro and the Micro. Information Systems 23, 327-344 (2007)

Meso, P., Datta, P., Mbarika, V.: Moderating Information and Communication Technologies' Influences on Socioeconomic Development with Good Governance: A Study of the Developing Countries. Journal of the American Society for Information Science and Technology 57, 186-197 (2006)

Meso, P., Musa, P., Straub, D., Mbarika, V.: Information Infrastructure, Governance, and Socio-Economic Development in Developing Countries. European Journal of Information Systems 18, 52-65 (2009)

Moon, M.J.: The Evolution of E-Government among Municipalities: Rhetoric or Reality? Public Administration Review 62, 424-433 (2002)

Norris, D.F., Moon, M.J.: Advancing E-Government at the Grassroots: Tortoise or Hare? Public Administration Review 65, 64-75 (2005)

Olphert, W., Damodaran, L.: Citizen Participation and Engagement in the Design of EGovernment Services: The Missing Link in Effective ICT Design and Delivery. Journal of the Association for Information Systems 8, 491-507 (2007)

Phang, C.W., Kankanhalli, A.: A Framework of ICT Exploitation for E-Participation Initiatives. Communications of the ACM 51, 128-132 (2008) 
Preacher, K.J., Hayes, A.F.: Asymptotic and Resampling Strategies for Assessing and Comparing Indirect Effects in Multiple Mediator Models. Behavior Research Methods 40, 879-891 (2008)

Romer, P.M.: Endogenous Technological Change. Journal of Political Economy 98, S71-S102 (1990)

Saebo, O., Rose, J., Flak, L.S.: The Shape of E-Participation: Characterizing an Emerging Research Area. Government Information Quarterly 25, 400-428 (2008)

Schultz, T.W.: Investment in Human Capital. American Economic Review 51, 1-17 (1961)

Shrout, P.E., Bolger, N.: Mediation in Experimental and Nonexperimental Studies: New Procedures and Recommendations. Psychological Methods 7, 422-445 (2002)

Siau, K., Long, Y.: Using Social Development Lenses to Understand E-Government Development. Journal of Global Information Management 14, 47-62 (2006)

Siau, K., Long, Y.: Factors Impacting E-Government Development. Journal of Computer Information Systems 50, 98-107 (2009)

Singh, H., Das, A., Joseph, D.: Country-Level Determinants of E-Government Maturity. Communications of the Association for Information Systems 20, 632-648 (2007)

Srivastava, S.C.: Is E-Government Providing the Promised Returns? A Value Framework for Assessing E-Government Impact. Transforming Government: People, Process and Policy 5, 107-113 (2011)

Srivastava, S.C., Teo, T.S.H.: The Relationship between E-Government and National Competitiveness: The Moderating Influence of Environmental Factors. Communications of the Association for Information Systems 23, 73-94 (2008)

Srivastava, S.C., Teo, T.S.H.: E-Government, E-Business, and National Economic Performance. Communications of the Association for Information Systems 26, 267-286 (2010)

Tan, C.W., Pan, S.L.: Managing E-Transformation in the Public Sector: An E-Government Study of the Inland Revenue Authority of Singapore (IRAS). European Journal of Information Systems 12, 269-281 (2003)

Tapscott, D.: The Digital Economy: The Promise and Peril in the Age of Networked Intelligence. McGraw-Hill, New York (1996)

Tornatzky, L.G., Fleischer, M.: The Processes of Technological Innovation. Lexington Books, Lexington (1990)

UN-Report.: UN Global E-Government Survey 2003: E-Government at the Crossroads (2003), http: / / www . unpan.org/egovkb/global_reports / 08 report.htm

UN-Report.: UN Global E-Government Readiness Report 2005: From E-Government to EInclusion (2005),

http: / /www. unpan.org/egovkb/global_reports / 08 report.htm

UN-Report. UN Global E-Government Survey 2010: Leveraging E-Government at a Time of Financial and Economic Crisis (2010),

http: / /www. unpan.org/egovkb/global_reports/08report.htm

Warkentin, M., Gefen, D., Pavlou, P.A., Rose, G.M.: Encouraging Citizen Adoption of E-Government by Building Trust. Electronic Markets 12, 157-162 (2002)

West, D.M.: E-Government and the Transformation of Service Delivery and Citizen Attitudes. Public Administration Review 64, 15-27 (2004)

West, D.M.: Global E-Government (2007), http: / / www . insidepolitics . org / 